\title{
DOES REMIFENTANIL-BASED ANESTHESIA CAUSE ACUTE OPIOID TOLERANCE?
}

\author{
Chantal Hickey MD, Christian Zaarour MD, Basem Naser MD, Mark W. Crawford MBBS \\ Department of Anesthesia, The Hospital for Sick Children, Toronto, Ontario, M5G 1X8
}

INTRODUCTION: The development of acute opioid tolerance with potent short-acting opioids such as remifentanil is described in animal studies, ${ }^{1}$ but the results of clinical studies are controversial. ${ }^{2,3}$ Remifentanil-based anesthesia is commonly used at our hospital to facilitate neurophysiologic monitoring during scoliosis surgery. We compared postoperative morphine consumption and visual analogue pain scores in children receiving remifentanil/propofol or morphine/propofol anesthesia for scoliosis surgery.

METHODS: With Research Ethics approval, 30 children aged 7 to 18 years scheduled to undergo posterior instrumentation for correction of idiopathic scoliosis were studied. Anesthesia was induced with propofol $4 \mathrm{mg} / \mathrm{kg}$, glycopyrrolate $10 \mathrm{~g} / \mathrm{kg}$, morphine $100 \mathrm{~g} / \mathrm{kg}$, and rocuronium $600 \mathrm{~g} / \mathrm{kg}$. The children were assigned randomly to one of two maintenance regimens: (1) in the remifentanil group, anesthesia was maintained with propofol infusion 50-80 g/kg/min, $\mathrm{N}_{2} \mathrm{O}$, and remifentanil starting at $0.25 \mathrm{~g} / \mathrm{kg} / \mathrm{min}$ and titrating in increments of $0.05 \mathrm{~g} / \mathrm{kg} / \mathrm{min}$ according to hemodynamic response, (2) in the control group, anesthesia was maintained with $\mathrm{N}_{2} \mathrm{O}$, intermittent morphine, and propofol starting at $200 \mathrm{~g} / \mathrm{kg} / \mathrm{min}$ and titrating in $25 \mathrm{~g} / \mathrm{kg} / \mathrm{min}$ increments according to hemodynamic response. Criteria for inadequate anesthesia included a heart rate or mean arterial pressure that exceeded $20 \%$ of the baseline value. In the remifentanil group, patients were given morphine $100 \mathrm{~g} / \mathrm{kg}$ approximately $30 \mathrm{~min}$ before the end of surgery. After extubation, morphine $50 \mathrm{~g} / \mathrm{kg}$ was administered by a blinded investigator as required for analgesia, followed by patient-controlled analgesia (PCA) with morphine. Initial 12- and 24-hour postoperative PCA morphine consumption and visual analogue pain scores were recorded.

RESULTS: Mean 12- and 24-hour PCA morphine consumption did not differ significantly between groups (figure). The 24-hour PCA morphine consumption in the remifentanil group was $1.47 \pm 0.39$ $\mathrm{mg} / \mathrm{kg}$ and that in the control group was $1.23 \pm 0.32 \mathrm{mg} / \mathrm{kg}$. Visual analogue pain scores did not differ between groups. There were no significant differences in the duration of anesthesia or intraoperative morphine administration.

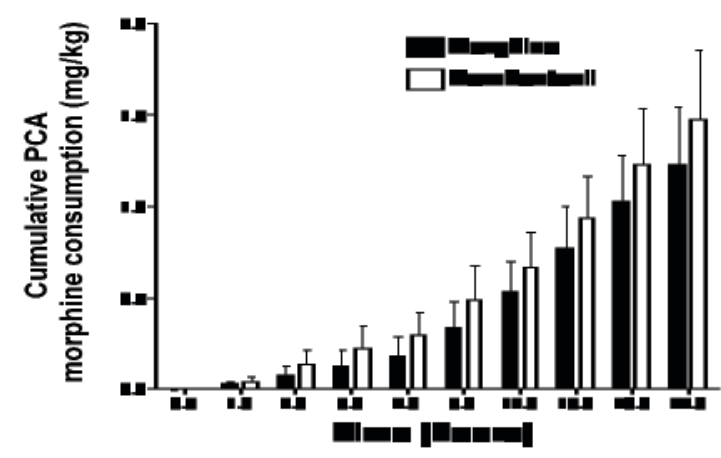

DISCUSSION: Remifentanil-based anesthesia did not cause a clinically significant increase in initial 12- and 24-hour PCA morphine consumption or visual analogue pain scores. These data do not support the development of acute opioid tolerance following remifentanil-based anesthesia in surgical patients.

REFERENCES: (1) Anesth Anal 83: 600-5 (2) Anesth 93:409-17 (3) Anesth Anal 89:753-7 